\title{
PERAWAT BERPERAN PENTING DALAM PENERAPAN K3 DI \\ RS
}

\author{
ANGEL OKTAVIA PURBA / 181101099 \\ angeloktavia013@gmail.com
}

\begin{abstract}
ABSTRAK
K3 adalah upaya yang bertujuan untuk meningkatkan dan memelihara derajat kesehatan fisik, mental dan sosial yang setinggi-tingginya bagi pekerja di semua jenis pekerjaan, pencegahan terhadap gangguan kesehatan pekerja yang disebabkan oleh kondisi pekerjaan; perlindungan bagi pekerja dalam pekerjaannya dari risiko akibat faktor yang merugikan kesehatan. Adapun tujuan dari penulisan ini adalah untuk mengetahui apa itu K3RS, apa tujuan dari K3RS dan bagaimana peran perawat dalam penerapan K3 di rumah sakit. Metode penulisan ini adalah Literature Riview, dimana ini menganalisis artikel yang relevan dan berfokus pada tema yaitu Peran perawat dalam penerapan K3 di RS. Berdasarkan pencarian literature didapatkan apa defenisi K3RS, tujuan dari K3RS dan juga didapatkan informasi tentang peran perawat dalam penerapan K3 di Rumah Sakit.
\end{abstract}

Kata Kunci : Keselamatan pasien, Peran Perawat, Penerapan K3 di RS

\section{ABSTRACT}

$K 3$ is an effort aimed at improving and maintaining the highest degree of physical, mental and social health for workers in all types of work, prevention of employee health problems caused by working conditions; protection for workers in their work from risks due to factors detrimental to health. The purpose of this paper is to find out what is K3RS, what is the purpose of K3RS and how is the role of nurses in the application of K3RS in hospitals. This writing method is Riview Literature, where it analyzes relevant articles and focuses on the theme, namely the role of nurses in the application of OSH in hospitals. Based on the literature search, what is the definition of K3RS, the purpose of K3RS and also information about the role of nurses in the application of K3RS in hospitals. 


\section{LATAR BELAKANG}

Kesehatan dan Keselamatan Kerja (K3) merupakan salah satu isu penting di dunia kerja saat ini termasuk di lingkungan rumah sakit. Angka kecelakaan kerja di rumah sakit lebih tinggi dibandingkan tempat kerja lainnya dan sebagian besar diakibatkan oleh perilaku yang tidak aman. Kesehatan dan Keselamatan Kerja (K3) merupakan salah satu isu penting di dunia kerja saat ini termasuk di lingkungan rumah sakit. Angka kecelakaan kerja di rumah sakit lebih tinggi dibandingkan tempat kerja lainnya dan sebagian besar diakibatkan oleh perilaku yang tidak aman. Kecelakaan kerja menjadi salah satu masalah urgen di lingkungan rumah sakit. Hal ini diakibatkan karena rumah sakit merupakan suatu unit pelayanan kesehatan yang memberikan pelayanan pada semua bidang dan jenis penyakit. Oleh sebab itu rumah sakit dituntut untuk dapat menyediakan dan menerapkan suatu upaya agar semua sumber daya manusia yang ada di rumah sakit dapat terlindungi, baik dari penyakit maupun kecelakaan akibat kerja (Ivana, Widjasena \& Jayanti, 2014). Pemerintah melakukan berbagai upaya untuk mengatasi kecelakaan kerja di rumah sakit, salah satunya dengan dikeluarkannya Undang-Undang Nomor 23 Tahun 1992 dan Undang-Undang Nomor 36 Tahun 2009 tentang penerapan Kesehatan dan Keselamatan Kerja di rumah sakit (Kepmenkes RI, 2010, p.8). National Safety Council (dalam Kepmenkes RI, 2007, p.4) menyebutkan bahwa terjadinya kecelakaan di rumah sakit $41 \%$ lebih besar dari pekerja di industri lain, selain itu Annizar (2012, p.3) menyatakan bahwa secara umum sebanyak 80-85\% kecelakaan kerja disebabkan oleh perilaku yang tidak aman. Beberapa komponen pelayanan kesehatan di rumah sakit, perawat adalah salah satu tenaga pelayanan kesehatan yang berinteraksi dengan pasien yang intensitasnya paling tinggi dibandingkan komponen lainnya. Perawat sebagai anggota inti tenaga kesehatan yang jumlahnya terbesar di rumah sakit (40- 60\%) dan dimana pelayanan keperawatan yang diberikan merupakan bagian integral dari pelayanan kesehatan memiliki peran kunci dalam mewujudkan keselamatan dan kesehatan kerja (K3) di Rumah Sakit (Depkes, 2007). 


\section{TUJUAN}

Adapun tujuan dari penulisan ini adalah untuk mengetahui apa itu K3RS, apa tujuan dari K3RS dan bagaimana peran perawat dalam penerapan $\mathrm{K} 3$ di rumah sakit.

\section{METODE}

Metode penulisan ini adalah Literature Riview, dimana ini menganalisis artikel yang relevan dan berfokus pada tema yaitu Peran perawat dalam penerapan K3 di RS. Adapun sumber yang digunakan dalam literature ini menggunakan sumber dari buku teks, jurnal dengan memasukan kata kunci Peran perawat dalam penerapan $\mathrm{K} 3$ di Rumah Sakit. Adapun jurnal yang saya yang digunakan merupakan jurnal yang diiterbitkan pada 10 tahun terakhir.

\section{HASIL}

Berdasarkan pencarian literature didapatkan apa defenisi K3RS, tujuan dari K3RS dan juga didapatkan informasi tentang peran perawat dalam penerapan K3 di Rumah Sakit.

\section{PEMBAHASAN}

Rumah sakit merupakan sarana pelayanan yang bergerak dibidang pelayanan jasa kesehatan yang mempunyai beragam persoalan tenaga kerja yang rumit dengan berbagai risiko terkena penyakit akibat kerja bahkan kecelakaan akibat kerja sesuai jenis pekerjaannya sehingga berkewajiban menerapkan upaya pembinaan Keselamatan dan Kesehatan Kerja Rumah Sakit (K3RS). Upaya ini dijalankan agar terhidar dari adanya risiko kecelakaan kerja (Astono, 2010). Kecelakaan kerja merupakan kejadian yang tidak terjadi secara kebetulan, melainkan ada sebabnya. Menurut WHO pengertian K3 adalah upaya yang bertujuan untuk meningkatkan dan memelihara derajat kesehatan fisik, mental dan sosial yang setinggitingginya bagi pekerja di semua jenis pekerjaan, pencegahan terhadap gangguan kesehatan pekerja yang disebabkan oleh kondisi pekerjaan; perlindungan bagi pekerja dalam pekerjaannya dari risiko akibat faktor yang merugikan kesehatan. Tujuan umum dari K3 adalah menciptakan tenaga kerja yang sehat dan produktif. Tujuan hyperkes dapat dirinci sebagai berikut (Rachman, 1990) : a. Agar tenaga kerja dan setiap orang berada di tempat kerja selalu dalam keadaan sehat dan selamat. b. Agar sumber-sumber produksi dapat 
berjalan secara lancar tanpa adanya hambatan. Keselamatan pasien (patient safety) adalah permasalahan yang sangat penting dalam setiap pelayanan kesehatan sehingga keselamatan merupakan tanggung jawab dari pemberi jasa pelayanan kesehatan terutama pelayanan keperawatan di setiap unit perawatan baik akut maupun kronis harus berfokus pada keselamatan pasien baik dalam tatanan rumah sakit. Penerapan keselamatan pasien ini dapat terlaksana dalam setiap tugas dan tanggung jawab yang akan dilakukan oleh perawat. Perawat dituntut untuk bertanggung jawab dalam setiap tindakannya khususnya selama melaksanakan tugas baik di rumah sakit, puskesmas, panti, klinik atau masyarakat. Meskipun tidak dalam rangka tugas atau tidak sedang melaksanakan dinas, perawat dituntut bertanggung jawab dalam tugas-tugas yang melekat dalam diri perawat. Perawat memiliki peran dan fungsi yang sudah disepakati. Tanggung jawab perawat erat kaitannya dengan tugas tugas perawat. Tugas perawat secara umum adalah memenuhi kebutuhan dasar serta mengutamakan dan mengoptimalkan keselamatan pasien. Terdapat beberapa faktor yang mempengaruhi kepatuhan perawat dalam melaksanakan K3RS diantaranya yaitu : -Pengalaman, pengalaman perawat dapat dilihat dari berbagai aspek. Salah satunya adalah masa kerja. Semakin lama masa kerja perawat maka pengalaman yang dimiliki juga semakin meningkat sehingga perilakunya dalam menjaga keselamatan dirinya juga menjadi lebih baik. Selain itu pengalaman juga dapat diperoleh dari berbagai sosialisasi maupun pelatihan tentang K3 yang dilakukan oleh pihak rumah sakit. Faktor selanjutnya yang ikut berperan dalam perubahan perilaku perawat yaitu tersedianya fasilitas yang mendukung sesuai dengan standar yang telah ditentukan. Faktor enabling (fasilitas keamanan dan keselamatan, hukum/aturan) pada perawat berpengaruh terhadap $\mathrm{K} 3$ pada perawat dalam penanganan pasien. Nilai yang paling tinggi pada faktor enabling berada pada komponen hukum/aturan, artinya secara umum perilaku seseorang dipengaruhi oleh aturan yang ada di lingkungannya. Selain beberapa faktor diatas, budaya organisasi juga berpengaruh terhadap perilaku perawat dalam melaksanakan keselamatan, dimana budaya organisasi yang baik akan mendorong perawat untuk bekerja 
sesuai dengan prosedur yang telah ditetentukan (Notoadmodjo, 2010)

Perawat sangatlah berperan penting dalam meningkatan kesehatan dan keselamatan kerja di Rumah sakit maka Perawat sebaiknya terus mengembangkan pengetahuan dan keterampilan di bidang manajemen keperawatan khususnya terkait Kesehatan dan Keselamatan Kerja (K3) sehingga pelayanan yang diberikan dapat lebih optimal dan berkualitas tanpa melupakan tingkat kesehatan dan keselamatan bagi pemberi asuhan keperawatan.

\section{KESIMPULAN}

Menurut WHO pengertian K3 adalah upaya yang bertujuan untuk meningkatkan dan memelihara derajat kesehatan fisik, mental dan sosial yang setinggi-tingginya bagi pekerja di semua jenis pekerjaan, pencegahan terhadap gangguan kesehatan pekerja yang disebabkan oleh kondisi pekerjaan; perlindungan bagi pekerja dalam pekerjaannya dari risiko akibat faktor yang merugikan kesehatan. Tanggung jawab perawat erat kaitannya dengan tugas tugas perawat. Tugas perawat secara umum adalah memenuhi kebutuhan dasar serta mengutamakan dan mengoptimalkan keselamatan pasien.

\section{SARAN}

Perawat sebagai pemberi layanan kesehatan memiliki tanggung jawab yang besar dalam memberi tindakan kepada pasien dimana dengan tujuan agar tercapainya derajat kesehatan. Setiap tindakan yang akan di berikan tentunya memiliki resiko tertentu yang dapat merugikan kklien ataupun perawat itu sendiri. Maka untuk menghindari hal tersebut perawat perlu dibekali ilmu pengetahuan dan pengalaman yang baik dalam pelaksnaan K3 di Rumah Sakit. 


\section{DAFTAR PUSTAKA}

Azrul, A. (1996). Menuju Pelayanan

Kesehatan Yang Bermutu. Jakarta :

Salemba Medika.

Departemen Kesehatan RI. (2008). Upaya Peningkatan Mutu Pelayanan Rumah Sakit. Jakarta: Depkes RI.

Efendi, Ferry, dan Makhfudli. (2009). Keperawatan Kesehatan Komunitas :Teori dan Praktik Dalam Keperawatan. Jakarta : Salemba Medika.

Ferry,Efendi dan Makhfudli.2009.Teori dan Praktik dalam Keperawatan.Jakarta: Salemba Medika

Firawati. (2012). Pelaksanaan Program Keselamatan Pasien di RSUD Solok. Jurnal Kesehatan Masyarakat, Vol 6, No 2.

Harus, B. D.(2015). Pengetahuan Perawat Tentang Keselamatan Pasien dengan Pelaksanaan Prosedur Keselamatan Pasien Rumah Sakit (KPRS) di Rumah Sakit Panti Waluyu Sawahan Malang. Jurnal CARE, Vol 3, No1.
Hidayat, A. Aziz Alimul. (2008). Pengantar Konsep Dasar Keperawatan. Jakarta: Salemba Medika.

Ismainar, Hetty. (2015). Keselamatan Pasien di Rumah Sakit. Yogyakarta: Deepublish.

Kusnanto. (2004). Pengantar Profesi \& Praktik Keperawatan Profesional. Jakarta : EGC.

Nursalam. (2002). Manajemen Keperawatan : Aplikasi Dalam Praktik Keperawatan Profesional. Jakarta : EGC.

Priharjo, Robert. (2008). Konsep dan Prespektif Praktik Keperawatan Profesional. Jakarta : EGC.

R.H Simamora. (2019). Buku Ajar Pelaksanaan Identifikasi Pasien : Uwais Inspirasi Indonesia.

R.H. Simamora. (2019). Documentation Of Patient Identification Into The Electronic System to Improve the Quality of Nursing Service. Internasional Journal of Sciiebtific \& Technology Research, Vol 08(09),18841886. 
R.H. Simamora. (2019). The Influence Of Training Handover Based SBAR Communication For Improving Patients Safety. Indian Journal of Public Health Research \& Development, Vol 09, 1280-1285.

Ulumiyah, N. H. (2018). Meningkatkan Mutu Pelayanan Kesehatan dengan Penerapan Upaya Keselamatan Pasien di Puskesmas. Jurnal Administrasi Kesehatan Indonesia, Vol 6(2) : 149155

Utarini, A, Djasri, H. (2012).Keselamatan pasien dan Mutu Pelayanan kesehatan. Jurnal Manajemen Pelayanan Kesehatan. 159160.

UU RI. (2014). Undang-Undang Republik Indonesia Nomor 38 Tahun 2014 Tentang Keperawatan. Jakarta: UU RI. 
